\section{International Scientific Journal Theoretical \& Applied Science}

p-ISSN: 2308-4944 (print) e-ISSN: 2409-0085 (online)

Year: 2017 Issue: 02 Volume: 46
Oleksandr V. Stovpets $\mathrm{PhD}$ in Philosophy, Doctoral applicant, Philosophy, Sociology \& Sociocultural activities management department, South Ukrainian National Pedagogical University named after K. D. Ushynsky, Associate Professor of Faculty of Law, Odessa National Maritime University http://orcid.org/0000-0001-8001-4223 a.stovpets@gmail.com

SECTION 30. Philosophy.

\title{
A PHILOSOPHIC VIEW OF THE SOCIAL-CULTURAL ROOTS FOR INTELLECTUAL PROPERTY'S INSTITUTIONALIZATION
}

\begin{abstract}
The relevance of research for historically occurred social and cultural roots of intellectual property as a special phenomenon, as well as intellectual property legal protection mechanism's development, was determined by the necessity of tracing those key events, which are associated with the transformation process of various intellectual-legal relations into single holistic social institution. To answer the question - why in fact human civilization has come to awareness of the need for legal protection of intellectual property, i.e. what cultural, ideological and socio-economic conditions have led mankind to regulate these specific relations? - would mean our approaching to the answer, why now there are so much contradictions in the realm of intellectual property, as well as in the areas of protection and enforcement of the rights and interests associated with intellectual-legal relations. An analysis for the socio-cultural genesis of intellectual property (i.e. an array of various historical reasons of the origin and evolution of the intellectual property phenomenon) will give us a better understanding of the nature of intellectual property (as a social institution) and its basic social functions.

Key words: intellectual property, society, social institution.

Language: Russian

Citation: Stovpets OV (2017) A PHILOSOPHIC VIEW OF THE SOCIAL-CULTURAL ROOTS FOR INTELLECTUAL PROPERTY'S INSTITUTIONALIZATION. ISJ Theoretical \& Applied Science, 02 (46): 173179.

Soi: http://s-o-i.org/1.1/TAS-02-46-29 Doi: crossef https://dx.doi.org/10.15863/TAS.2017.02.46.29

\section{ФИЛОСОФСКИЙ ВЗГЛЯД НА СОЦИОКУЛЬТУРНЫЕ ИСТОКИ ИНСТИТУЦИАЛИЗАЦИИ} ИНТЕЛЛЕКТУАЛЬНОЙ СОБСТВЕННОСТИ

Аннотация: Актуальность исследования исторически сложивиихся социиальных и культурных корней интеллектуальной собственности как особого явления, а также истории становления механизма правовой охраны интеллектуальной собственности, определяется необходимостью проследить те ключевые события, с которыми связан процесс трансформации различных интеллектуально-правовых отнотений в единый самостоятельный социальный институт. Ответить на вопрос - почему собственно человеческая ичвилизация пришла к осознанию необходимости правовой охраны интеллектуальной собственности, т.е. какие духовно-культурные и социально-экономические предпосылки побудили человечество к упорядочению этих специфических отношений? - будет означать приближение к ответу, почему же ныне возникает множество противоречий в сфере использования интеллектуальных продуктов, а также в сферах охраны и защиты прав, связанных с реализачией интеллектуально-правовых отношений. Анализ социокультурного генезиса интеллектуальной собственности (т.е. того массива различных исторических оснований происхождения и эволюиии феномена интеллектуальной собственности) даст лучшее понимание природы современного концепта социального института интеллектуальной собственности (и его основных соичиальных функций).
\end{abstract}

Ключевые слова: интеллектуальная собственность, общество, социальный институт.

Introduction

Известный нам сегодня концепт интеллектуальной собственности - это продукт длительной социальной эволюции. Подобно тому, как государство и право возникают на определённой ступени общественной зрелости, так и феномен интеллектуальной собственности некогда выделился из системы отношений 
собственности и постепенно оформился в специфический социальный институт, обретя известные нам очертания. Но как же это происходило? И каковы основные причины и закономерности процесса институцииализации (т.е. преобразования из явления в общественный институт) для данного вида собственности? Наконец, какие функции присущи институту интеллектуальной собственности, т.е. какие главные задачи он выполняет в жизни социума? Попробуем ответить на все эти вопросы в данном исследовании (которое выполняется в рамках докторской диссертации, посвящённой социально-философским аспектам института интеллектуальной собственности).

\section{Materials and Methods}

Философские предпосылки формирования интеллектуальной собственности как явления складываются на заре западноевропейской цивилизации в период античности, когда была осуществлена рефлексия накопленного знания и возможных способов его бытия. Известно, что ещё в IV веке до н.э. Платон сформулировал концепцию, в которой обосновал различие материального мира (мира вещей) и нематериального (мира идей). Согласно Платону, «истинное бытие - это умопостигаемые бестелесные идеи», данные же ощущению эмпирические тела, вещи и явления - не истинны, поскольку вообще относятся не к «бытию», а к чему-то подвижному, к «становлению» [1].

Упомянутая концепция, естественно, не предполагала какого-либо индивидуального права собственности на идеи - поскольку идеи первичны, они принадлежат всем (а может, все находятся в их власти) в одинаковой степени. Поэтому в рамках платоновской концепции, где идея (эйдос) как таковая не может принадлежать одному человеку, говорить о наличии каких-то существенных признаков интеллектуальной собственности не имеет смысла. Возникновение этой проблематики относится к более позднему периоду.

А вот понятие гонорара как формы оплаты творческого труда (например, за изваяние из мрамора) были известны ещё римскому праву. Однако в целом юридическому оформлению экономической стороны творчества долгое время не придавалось особого значения, так как возможность торговать результатами интеллектуальной, творческой деятельности возникла сравнительно поздно. До этого продукция творчества распространялась «вне рынка», не являясь предметом экономического оборота, в отличие, например, от аграрной или ремесленной продукции. Стало быть, само наличие такого явления, как «гонорар», ещё не позволяет говорить о становлении института интеллектуальной собственности, поскольку на тот момент не были ещё созданы надлежащие законодательные предпосылки для его функционирования, а существовавшие тогда экономические предпосылки находились в зачаточном состоянии [2].

В эпоху, предшествовавшую изобретению печатного пресса (с подвижными литерами) И. Гутенбергом около 1440 года, положение произведений творческого труда, наиболее вероятно, регулировалось правом «вещной» собственности. Автор произведения (рукописи, скульптуры, картины) являлся собственником этого материального объекта и мог передать или продать его другому лицу. При этом формы воспроизводства интеллектуального потенциала общества базировались в основном на системе меценатства - творческих людей субсидировали правители, духовенство, иные влиятельные люди своего времени.

По мере роста влияния буржуазии и развития рыночных отношений, авторы начинают более активный поиск способов получения вознаграждения за своё творчество: система средневековых «привилегий» постепенно сменяется законами, признающими за авторами право на монопольное использование принадлежащих им произведений и технических новинок в течение установленного срока. Такое «право» изобретателей было впервые упомянуто в Венецианской республике, в тексте Венецианского Патентного Статута от 19 марта 1474 года - Venetian Statute on Industrial Brevets в котором уже признавались их «моральное право» и исключительное право на использование своего изобретения в течение ограниченного периода времени. А первый из известных европейской истории патент был выдан ещё раньше: в 1421 году великий архитектор и скульптор Ф. Брунеллески, будучи обеспокоенным крайне медленной погрузкой мраморных плит для своей мастерской, придумал и установил на барже уникальный по конструкции поворотный корабельный кран. Это позволило значительно ускорить такелажные работы. По инициативе изобретателя в том же году городской управой Флоренции на имя Ф. Брунеллески был выдан патент (от лат. patens - открытый, ясный, очевидный), который удостоверил авторство и закрепил привилегии. Архитектор оказался весьма прозорлив, потому что вскоре германский торговый союз (Ганза) купил у него первую лицензию на использование этого изобретения. Через полвека был издан ранее упомянутый Венецианский Статут [3]. Однако полноценное законодательное воплощение идея защиты интеллектуальной собственности получила несколько веков спустя уже в Северной Европе. 
Первые законы об интеллектуальной собственности появились в Англии только после распространения книгопечатания: этот механический процесс кардинально повысил интенсивность информационного обмена, в первую очередь, - тиражируемость литературных и иных письменных произведений. Технология книгопечатания вызвала к жизни особые профессии - печатников и книготорговцев, называемых в Англии «stationers» (торговцы печатной продукцией, книгоиздатели).

С социально-экономической точки зрения возникновение этих видов профессиональной деятельности стало первым поворотным моментом в развитии социального института интеллектуальной собственности. Ведь уже тогда книгоиздатели были первыми лоббистами в сфере интеллектуальной собственности, хотя до её современного понимания тогда было ещё очень далеко.

Книготорговцы инвестировали немалые суммы в покупку бумаги, в приобретение или изготовление печатных машин, а также тратили деньги на оплату труда рабочей силы. Всё это предусматривало авансирование средств, которые только по прошествии определённого времени могли быть возмещены поступлениями от реализации печатной продукции. Выражаясь современной терминологией, развитие нового для той эпохи издательского дела было связано с необходимостью т.н. венчурных инвестиций. В этой ситуации без какой-либо законной формы защиты от нечестной конкуренции (например, от изготовления и продажи незаконных копий) инвестирование в книгопечатание было достаточно рискованным предприятием, грозившим книготорговцам полным разорением [4].

C социально-философской точки зрения важно заметить, что на заре развития интеллектуальной собственности нашла свою реализацию следующая логичная культурноэкономическая тенденция: 1) развитие духовной культуры находило объективацию (фиксацию) в таких материальных источниках, как книги; 2) востребованность в распространении знаний и их носителей - книг - стимулировала развитие технической мысли, что, в конечном счёте, привело к технологическим инновациям (была изобретена технология книгопечатания, которая, по мере совершенствования, превратилась в целый комплекс производственных процессов со всеми вытекающими социальноэкономическими дивидендами); 3) возникшая новая сфера деятельности стала той средой, в которой зародились новые социальные отношения, со своим специфическим субъектным составом - авторами (в широком смысле), издателями, книготорговцами, - каждый со своими далеко не совпадающими интересами; 4) усложнение социально-экономических отношений в творческой, интеллектуальной среде потребовало соответствующего юридического регулирования, вызвало к жизни новые юридические принципы, механизмы, и сформировало новые правовые институты; 5) изменение правового статуса творческих интеллектуалов, переосмысление ими своих возможностей, своего социокультурного и экономического значения - всё это повлияло на дальнейшее развитие цивилизации, привело к реинтерпретации ценности информации (и интеллектуальной собственности как особой разновидности информации, значение которой весьма актуально в постиндустриальную эпоху).

Иными словами, интеллектуальная продукция (вернее, социальная потребность в её тиражировании): a) простимулировала развитие изобретательства (как разновидности интеллектуальной деятельности) и новой социально-экономической сферь (издательского дела), б) явилась предпосылкой к обособлению новой прослойки интеллектуалов в тогдашней структуре социума (авторы, издатели, распространители), и социальный запрос на развитие нового правового института - права интеллектуальной собственности (которое в течение нескольких столетий эволюционировало вплоть до превращения в относительно самостоятельную частноправовую структуру, и теперь в большинстве правовых систем рассматривается в качестве подотрасли гражданского права).

Однако вернёмся к историческим истокам института интеллектуальной собственности. Риск значительных экономических убытков в сочетании с привлекательностью самого издательского бизнеса привёл к усилению лоббирования внесённого законопроекта об интеллектуальной собственности в английском парламенте, и к прессингу на монархическую верхушку с целью обеспечения правовой защиты от незаконного копирования. Первым британским документом, регламентирующим вопросы интеллектуальной собственности, считается Статут королевы Мэри I (Англия, 1557 г.), который закреплял за издателем монопольное право далее издавать однажды выпущенную им книгу (неважно, новую или давно известную) при условии, что она одобрена официальной цензурой. Так возникла система т.н. «привилегий», которые суверен выдавал определённым издателям. Эта система привилегий использовалась верховной властью для цензуры массовой информации. C конца XV и до начала XVIII века история книгопечатания в основном связана с выдачей привилегий, закреплённых в королевских законах и указах. Нужно отметить, 
что права авторов в Статуте Мэри I не упоминаются совсем.

На рубеже XVII - XVIII столетий старый порядок был поколеблен. На смену британской абсолютной монархии приходит система парламентаризма. Срок действия последнего закона, регулировавшего деятельность издателей, - Акта о лицензировании 1662 года, - истёк в 1695 году. Этот акт предоставлял издателям монополию на публикации, дабы облегчить королевским властям контроль над изданиями. По истечении срока его действия никакого специального закона, наделявшего издателей и книготорговцев эксклюзивным правом печатать и продавать книги, не осталось [5, с. 104].

В обстановке хаоса, вызванного крушением системы королевских привилегий, издатели и книготорговцы - в первую очередь, члены влиятельной издательской группы «Угорь», контролировавшей почти всю книготорговлю в Англии XVIII века, - стремясь сохранить ранее полученные ими эксклюзивные права, вновь усиливают лоббирование в парламенте. Они претендовали на вечное право контролировать «копирование» книг, однажды приобретенное у авторов. И нужно сказать, что им тогда удалось значительно продлить жизнь своей книгоиздательской монополии: в 1774 году, почти через 180 лет после написания Шекспиром «Ромео и Джульетты», исключительное право издания данного произведения в Англии всё ещё принадлежало правопреемникам Д. Тонсона в лондонской издательской группе «Угорь» [6]. Но всё это было позднее.

А ранее, в результате давления издательского лобби на монархическую верхушку, 11 января 1709 года в Палате общин был заслушан проект закона «О поощрении образования путём закрепления за авторами или приобретателями копий печатных книг прав на последние на время, устанавливаемое отныне». 10 апреля 1710 года проект стал законом, известным под названием «Статут королевы Анны» (Statute of Annae Reginae, или Copyright Act 1709). Это был первый в истории закон об авторском праве в современном понимании указанного термина, который впервые закрепил личное право на охрану опубликованного произведения [7].

До появления Статута Анны в 1709 году, как только произведение было написано и первый раз издано (выпущено в свет), автор утрачивал над его распространением всякую власть. Но это обстоятельство не было особенно значимым: ведь пока рынок довольствовался авторскими экземплярами произведений или услугами переписчиков - отношения между авторами, книготорговцами, читателями не носили комплексного экономического характера. В этой сфере было слишком мало денег, чтобы вызвать интерес у буржуазии и государства.

Однако с появлением технологической возможности тиражирования произведений посредством книгопечатания забрезжила перспектива превращения книгоиздания в индустрию, приносящую большие прибыли. Это привело к осознанию в обществе необходимости регламентации нового типа отношений, в частности, защиты прав «добросовестных» издателей (заключивших с автором договор и выплачивающих ему определённый процент с продаж, роялти) от подпольных издателей, занимающихся контрафакцией. То есть фигура автора, действительно получавшего некоторую защиту согласно Статуту Анны, была необходима для того, чтобы формализовать и чётко определить разницу между «добросовестным» издателем, у которого есть контракт с автором, и правонарушителем нового типа - нелегальным издателем, занимающимся продажей плодов чужой творческой деятельности без договора с автором.

В то же время, данный закон вывел на сцену и новые фигуры пострадавших - в первую очередь, автора, ставшего с этого момента для издателя неразлучным спутником. Т.е. в течение ближайших 14 лет с момента первой публикации автор «прикреплялся» к издателю, который приобрёл монополию печатать произведение. И хорошо, если издатель оказывался добросовестным и исправно платил роялти. Тем не менее, важным соииальным последствием Статута Анны 1709 года можно считать то, что впервые на государственно-правовом уровне обозначилось принципиальное отличие интеллектуальной собственности от материальной. Отныне самого факта владения экземпляром книги стало недостаточно для того, чтобы делать с её содержанием всё, что заблагорассудится. Поскольку принципиальным становится вопрос: а есть ли договор с автором? Тиражирование (бывшее в то время единственным приносящим очевидную выгоду способом донесения мысли автора до большого количества людей), начиная с 1710 года, может легитимно производиться только с согласия автора и на определённых условиях [8, с. 53].

Несмотря на несовершенство раннего законодательства об интеллектуальной собственности, для авторов и издателей вскоре стало очевидным, что Статут 1710 г. открыл новый тип отношений, разделявший материальное воплощение произведения (вещное право) и право на использование уникального информационного содержания (авторское право). Именно вокруг последнего правообладатели и стали выстраивать поддерживаемую законом 
монополию, действие которой, впрочем, было ограничено указанными выше сроками.

Постепенно возникает представление о том, что недостаточно наделить автора книги (или его издателя) одним правом на печатание и распространение произведения. Открытым оставался вопрос о публичных исполнениях (спустя время они стали объектом т.н. смежных прав), о картинах, о песнях и музыке, о произведениях в сфере хореографии, скульптуры и архитектуры, о репродукциях, переводах и т.д. Несколько лет спустя английский художник, иллюстратор, гравёр и теоретик искусства У. Хогарт, рисунки которого неоднократно подделывались, возглавил борьбу с целью узаконить охрану интересов «гравёров, рисовальщиков и живописцев». Эта борьба успешно завершилась в 1735 г. принятием «Закона о гравёрах». С этого момента законодательство об интеллектуальной собственности начинает экспансию в отношении объектов своего воздействия. И эти процессы происходили не только в Англии.

В США первые законы штатов об авторском праве появились ещё до французской и американской революций. Так, в Законе штата Массачусетс от 17 марта 1789 года указывалось, что «...нет собственности, принадлежащей человеку более, нежели та, которая является результатом его умственного труда». Вскоре и в США была осознана необходимость принять федеральный закон об авторском праве. Конституция Соединенных Штатов предоставила Конгрессу право «поощрять развитие наук и ремёсел», обеспечивая на определённый срок авторам и изобретателям исключительное право на их произведения (writings) и изобретения (inventions). В свете этой статьи Конституции в 1790 г. и был принят первый федеральный закон об охране книг, карт и схем. Более позднее законодательство распространило охрану также и на спектакли, фотографии, тексты песен и другие формы творчества [9, с. 62].

Наконец, украинское законодательство о «копирайте» нашло своё наиболее концентрированное выражение в Законе Украины «Об авторском праве и смежных правах» 1993 года [10], а также в Книге IV Гражданского кодекса Украины [11], который действует с 2003 г. Эти нормативно-правовые акты - в комплексе с законодательством о праве промышленной собственности, о торговых марках и коммерческих наименованиях, о селекционных достижениях и других результатах интеллектуальной, творческой деятельности отражают правовую сторону функционирования, развития интеллектуальной собственности как многогранного социильного института.
Учитывая формат данного исследования, приходится ограничиться изложенным выше анализом социокультурных истоков лишь одной из граней интеллектуальной собственности авторского права (копирайта). Однако картина, полученная в процессе такого анализа, является достаточно иллюстративной. Принимая во внимание цель настоящего исследования проследить ключевые социокультурные закономерности, реализация которых на определённом этапе общественного развития позволила интеллектуальной собственности из явления превратиться в целый социальный институт - мы видим возможным и необходимым сформулировать некоторые выводы.

\section{Conclusions}

Во-первых, технологические и социальноэкономические предпосылки трансформации и институциализации интеллектуально-правовых отношений возможно проследить примерно с середины XV века, когда был изобретён печатный станок как средство ретрансляции произведений, а также выданы первые патентные грамоты как средства охраны изобретений.

Во-вторых, оформление специфического института интеллектуальной собственности (и в социологическом, и в экономическом, и в юридическом понимании) является вполне закономерным результатом культурного, технологического и социально-экономического развития общества. Активное развитие отношений интеллектуальной собственности c переходом этих отношений на новый уровень (то есть, собственно - институцчиализация в сфере интеллектуальной собственности, формирование нового социального института, а также международно-правовая унификация соответствующих общественных отношений) начались ещё в индустриальную эпоху, в течение XVIII - XIX столетий. Но если сравнивать социальную динамику развития интеллектуально-правовых отношений до середины XVIII ст., в «доиндустриальные» времена, и в последовавшую эпоху т.н. «первой» и особенно «второй промышленной революции» (когда были изобретены электричество, телеграф, конвейер, когда произошёл переход от угля к нефти и т.д.), то можно констатировать: до начала индустриальной эры наиболее активно развивался «копирайт», после - право промышленной собственности (в первую очередь, патентное). Собственно, первым международным правовым актом в сфере интеллектуальной собственности стала Парижская конвенция об охране промышленной собственности 1883 г. 
Однако наибольшую интенсивность обозначенный процесс институциализации обрёл с переходом цивилизованного человечества в постиндустриальную эпоху, начало которой связано с т.н. «третьей промышленной революцией» - цифровой, в 1980-х. Она продолжается и сейчас. А это, в свою очередь, побуждает социальную философию к переосмыслению феномена интеллектуальной собственности, и к реинтерпретации отдельных аспектов института интеллектуальной собственности в новых социокультурных условиях.

Ведь именно сегодня интеллектуальная собственность - как особый вид информации приобретает колоссальное социальноэкономическое значение и наиболее весомый правовой статус за всю историю существования данного феномена. Следовательно, о полноценной трансформациии интеллектуальной собственности в социиальный институт можно говорить сейчас, в эпоху постиндустриальной экономики, когда возник новый класс людей, работающих исключительно в инновационной сфере и имеющих дело преимущественно с информационными технологиями. И поскольку именно в постиндустриальном обществе информация становится особенной сферой и особым предметом общественных отношений, то и интеллектуальная собственность становится одним из ключевых социальных институтов современности (когда в культурном плане человечество, вероятно, находится в состоянии перехода из Модерна в Постмодерн).

Проведенное в данной статье исследование культурно-исторических факторов развития интеллектуальной собственности позволяет утверждать, что она в проиессе своей институциализации (т.е. по мере своего преобразования из феномена - в социальный институт) проходит ряд последовательных этапов, которые предметно описывались выше, а именно укладывается в следующую схему: 1. возникновение потребности, удовлетворение которой требует совместных организованных действий группы людей; 2. формирование общих для группы людей целей (тогда же возникает и соответствующее лобби); 3. появление в ходе стихийного социального взаимодействия (с людьми, не входящими в упомянутую группу) социальных норм и правил; 4. выработка процедур, связанных с реализацией норм и правил; 5. постепенное всеобщее восприятие норм и правил, и процедур их реализации, в процессе их практического применения; 6. установление системы санкций для поддержания норм и правил, и дифференцирование их применения в различных случаях; 7. создание системы статусов и ролей, охватывающих всех субъектов, принимающих участие (прямо или косвенно) в соответствующих отношениях, на которые распространяется данный социальный институт.

Наконец, рассматривая интеллектуальную собственность в качестве социального института, можно дать ей следующее определение: институт интеллектуальной собственности - это специфический социальный механизм, представленный набором постоянно повторяющихся и воспроизводящихся общественных отношений в сфере создания, владения, использования, распоряжения, охраны u всех иных возможных социальных практик в отношении результатов интеллектуальной, творческой деятельности.

Иными словами, институт интеллектуальной собственности - это система воспроизводства общественных взаимодействий в отношении интеллектуальной, творческой, инновационной продукции. Механизмы, лежащие в основе этой системы, функционируют с опорой как на официальные кодифицированные своды законов, так и на неформализованные правила (которые нередко обнаруживаются только при их нарушении).

Как и любому социальному институту, интеллектуальной собственности присущи свои социальные функции. Среди них: 1) функция закрепления и воспроизводства общественных отношений (т.е. складывается определённый алгоритм, который обеспечивает устойчивые модели социального взаимодействия касательно разных видов и форм интеллектуальной собственности); 2) регулятивная функция (выстраивает взаимоотношения между членами общества путём выработки образцов поведения, устанавливает рамки и обеспечивает порядок, при котором участники отношений в сфере интеллектуальной собственности в абсолютном большинстве демонстрируют предсказуемость и стандартное поведение, выполняют ролевые требования и ожидания); 3) интегративная функция (обеспечивает сплочённость, связь, детерминированность и взаимную ответственность участников интеллектуальноправовых отношений, с опорой на созданные социальные нормы, ценности, правила, систему ролей и санкций); 4) транслирующая функция (поскольку общество не может развиваться без передачи социального опыта, то, как и любой институт, интеллектуальная собственность для своего нормального функционирования нуждается в приходе новых людей, усвоивших общепринятые правила; таким образом, социальные границы института интеллектуальной собственности меняются по мере смены поколений, чем обеспечивается преемственность и дальнейшая социализация); 
5) коммуникативная функиия (реализуется через усвоение информации, произведенной в процессе функционирования института интеллектуальной собственности, и рассчитанной на потребление разными социальными группами). Конечно, это не исчерпывающий перечень социальных функций института интеллектуальной собственности, но их можно обозначить в качестве неотъемлемых - некогда обеспечивших его формирование (институциализацию), и поддерживающих его развитие (трансформацию, адаптацию и т.д.) и постоянное функционирование.

\section{References:}

1. Plato (1999) Sobranije sochinenij [Collected works]; in 4 volumes. - Moscow: Mysl'. (rus).

2. Landes WM, Posner RA (2003) The Economic Structure of Intellectual Property Law. Cambridge, MA: Harvard University Press. (eng).

3. Bently L, Kretschmer M (1474) Venetian Statute on Industrial Brevets, Primary source: Scanned from the Manuscript held in the Venetian State Archives, Venice, Senato Terra, ASV, reg. 7, c. 32r. - [Electronic source]. Available: http://www.copyrighthistory.org/ http://www.copyrighthistory.org/cam/tools/requ est/showRepresentation?id=representation_i_14 74 (Accessed: 10.02.2017).

4. Walker Keith (1992) Jacob Tonson, Bookseller // The American Scholar. - Vol. 61, No. 3, Summer 1992. - P. 424-430. (eng).

5. Lessig Lawrence (2004) Svobodnaya Kultura [FREE CULTURE: How Big Media Uses Technology and the Law to Lock Down Culture and Control Creativity]; The Penguin Press, Creative Commons // transl. by O. Danilov, ed. by V. Il'yin. - Moscow: Pragmatika Kultury, 2007. - 272 p. (rus).

6. Gomez-Arostegui HT (2010) The Untold Story of the First Copyright Suit under the Statute of Anne in 1710 // Berkeley Technology Law Journal. - 2010. - 25: 1247-1350. (eng).
7. Vaidhyanathan S (2004) The Anarchist in the Library: How the Clash between Freedom and Control is Hacking the Real World and Crashing the System. - New York: Basic Books, 2004. - P. 40. (eng).

8. Minkov AM (2001) Mezhdunarodnaya ohrana intellektual'noy sobstvennosti [International protection for intellectual property]. - St.Petersburg: Piter, 2001. - 720 p. (rus).

9. Bezmolitvenniy AS (2010) Social'nofilosofskiye aspekty intellektual'noy sobstvennosti v seti Internet [Social-philosophic aspects of the intellectual property in the Internet]; thesis of the candidate of philosophical sciences: 09.00.11. - Moscow: Lomonosov Moscow State University, 2010. 154 p. (rus).

10. (1993) Zakon Ukraïny «Pro avtors'ke pravo i sumizhni prava» [The Law of Ukraine «On Copyright and Related Rights»]; adopted on 23.12.1993 № 3792-XII // The Official Bulletin «Vedomosti Verkhovnoyi Rady Ukrainy». 1994. - № 13. - Clause 64 (the valid current edition on 27.10.2016). (ukr).

11. (2003) Cyvil'nyj kodeks Ukraïny. [The Civil Code of Ukraine]; Act dated on 16.01.2003 № 435-IV // Official Bulletin of Ukraine. 2003. - № 11. - Clause 461 (the valid current edition on 02.11.2016). (ukr). 